ISSN: 1641-4713; e-ISSN: 2081-1160

DOI: https://doi.org/10.36551/2081-1160.2021.28.205-224

\title{
Chile: La Redemocratización en Clave Castrense
}

\author{
Chile: The Redemocratization in Martial Key
}

\author{
Marcial Saavedra Castro \\ Universidad Federal de Bahía (Ufba), Brasil \\ ORCID iD: https://orcid.org/0000-0002-7452-6043 \\ E-mail: marcialhumberto@ hotmail.com \\ Lina Aras \\ Universidad Federal de Bahía (Ufba), Brasil \\ ORCID iD: http://orcid.org/0000-0003-0654-9777 \\ E-mail: laras@ufba.br
}

Recepción: 25.05.2021

Aprobación: 17.09.2021

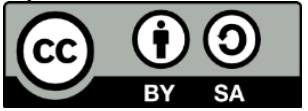

Resumen: Este artículo pretende investigar el proceso de redemocratización en América Latina, específicamente en Chile. En este sentido, se parte del concepto de "economía neoliberal" y de la "Doctrina de Seguridad Nacional, DSN", pilares claves del proceso de militarización de la sociedad chilena a partir de la intervención castrense de 1973 y de la refundación del Estado a partir del binomio represión política y neoliberalismo. La redemocratización chilena se caracterizó por los expedientes de contención expresados en la Constitución de 1980, destinados a frenar las iniciativas del primer gobierno civil post dictadura, electo en 1990, así como a los gobiernos posteriores. De este modo, se hace una revisión de la literatura sobre las particularidades de la transición política del país, destacando el rol de sus protagonistas civiles y militares, así como de la sociedad organizada que retomó gradualmente su espacio público. Se concluye que el tránsito desde la dictadura a la democracia fue un proceso marcado por ambigüedades y reticencias resultando en gobiernos civiles tutelados y restringidos.

Palabras clave: golpe de estado, neoliberalismo, transición, redemocratización

Abstract: This article aims to investigate the re-democratization process in Latin America, specifically in Chile. In this sense, it starts from the concept of "neoliberal economic" and the "National Security Doctrine" DSN", which are the key pillars of the Chilean society's militarization process, 
from the military intervention of 1973 and the re-founding of the State from the binomial repression politics and neoliberalism. The Chilean re-democratization was characterized by the containment files expressed in the 1980 Constitution aimed at curbing the initiatives of the first post-dictatorship civil government, elected in 1990, and subsequent governments. Therefore, this work presents a literature review based on the country's political transition particularities, highlighting its civil and military protagonists' role and the organized society that gradually returned to its public space. It is concluded that the transition from dictatorship to democracy was a process marked by ambiguities and reluctance, resulting in protected and restricted civil governments.

Keywords: coup d'état, neoliberalism, transition, redemocratization.

\section{INTRODUCCIÓN}

El proceso de redemocratización chileno se diferenció de los otros países sudamericanos, primero, por las peculiaridades de la dictadura militar caracterizada por la personalización y verticalización del poder, así como por la violencia política desatada por los órganos de represión contra los opositores a partir del golpe de Estado en 1973 dentro y fuera del país y; segundo, por la compleja ecuación que envolvió la transición y la posterior redemocratización.

Durante los 16 años en que los militares estuvieron en el poder, el general Augusto Pinochet ejerció la plena potestad llevando a cabo la desarticulación del Estado y la implantación de una política económica neoliberal con la participación de los economistas formados en la Escuela de Chicago, responsable de la privatización de los servicios esenciales como la educación, la salud o la seguridad social, entre otros (Fontaine, 1988).

La represión selectiva a los partidos de izquierda y la atomización de las organizaciones sociales fue imprescindible para imponer el "orden" dentro del país a partir del terror político y la eliminación de cualquier foco de resistencia, acorde con la orientación de la Doctrina de Seguridad Nacional (DSN) (Comblim, 1978). En ese ambiente, Pinochet convocó, en 1980, a la población chilena para una consulta nacional para aprobar una nueva Constitución con la cual buscaba, no solo resguardar el régimen sino también institucionalizarlo políticamente dándole un carácter legal y, además, consagrándolo como Jefe Supremo de la nación y estableciendo que, en 1988, la sociedad decidiría vía plebiscito sobre la permanencia o no de Pinochet en el poder durante ocho años más; esto es, un nuevo mandato entre 1989 y 1997.

El 5 de octubre de 1988, la sociedad chilena votó mayoritariamente en contra, con un 54\% de los votos, lo que representó una derrota política para Pinochet y la posibilidad de elegir democráticamente en 1989 un gobernante civil, 
perspectiva que la sociedad chilena celebró con ahínco, ya que implicaba acabar con 16 años de dictadura militar y la memoria represiva del periodo. Sin embargo, a pesar del resultado electoral, el general permaneció en el poder hasta marzo de 1990, transformando esos últimos meses antes de la transferencia del mando al presidente civil como uno de los más acelerados en producir enclaves jurídicos y políticos dentro del nuevo sistema (Ramos, 2020, p. 172).

En ese contexto de transferencia de poder, la estrategia que orientó tanto a Pinochet como a los militares fue la de salvaguardar aspectos capitales y auspiciosos para el régimen presentes en la Constitución de 1980, tales como la autonomía de la Fuerzas Armadas y la de su círculo más estrecho dentro de un horizonte democrático, así como el tutelaje político mediante los senadores designados con el objetivo de evitar mayorías legislativas para cambiar leyes consideradas sensibles por los militares. Surgió así, un tenso y complicado periodo de negociación y acuerdos políticos entre civiles y militares, incluidos los preparativos para la elección presidencial y los correspondientes registros electorales programados para el mes de diciembre de 1989. Dichos acuerdos serían fundamentales para conducir, no sólo la fase de transición, sino el futuro de la democracia chilena interrumpida en septiembre de 1973.

Dicha transición, que comenzó con el plebiscito de 1988 y terminó el 11 de marzo de 1990 (Garretón, 1991), favoreció la emergencia y organización de importantes movilizaciones populares que desde el inicio de los ochenta venían enfrentando a la dictadura y que, posteriormente, fueron protagonistas de primera línea en la campaña contra Pinochet y en las elecciones del 14 de diciembre de 1989. El reencuentro con las urnas dio la victoria al candidato de la Concertación ${ }^{1}$, Patricio Aylwin, con un 55,2\% de los votos. Sin embargo, a partir de ese resultado electoral, la democracia chilena fue tensionada: primero, por la permanencia de Pinochet en el poder hasta 1990 y, segundo, por el peso que representó gobernar el país en democracia, pero con una muralla constitucional erguida para frenar los tímidos ritos de la redemocratización.

El objetivo de este artículo es analizar el proceso de redemocratización chilena que difiere de sus congéneres sudamericanas en tres aspectos: primero, por el contexto histórico que llevó Salvador Allende al gobierno y la relevancia de la "vía chilena al socialismo"; segundo, por la compleja trama nacional

\footnotetext{
${ }^{1}$ La Concertación de Partidos por la Democracia fue creada el 2 de febrero de 1988, meses antes del plebiscito, reuniendo las principales fuerzas de oposición al régimen de Pinochet. Entre los partidos que la formaban destacaba el Partido Demócrata Cristiano (DC); el Partido Socialista (PS); El Partido por la Democracia (PPD) y el Partido Radical Socialdemócrata (PRSD); entre otros.
} 
e internacional que condujo al golpe de Estado de 1973 y a la consecuente implantación del modelo neoliberal; y, por último, el largo y engorroso proceso de transición y de redemocratización chilena. El epígrafe siguiente discurre sobre el periodo que marcó las dos transiciones chilenas: la transición al socialismo y la transición democrática. La primera fue abortada por el golpe de Estado y el quiebre institucional que puso fin al gobierno de la Unidad Popular y desató una violenta represión. La otra tuvo como referente la aprobación de la Constitución de 1980, definiendo el calendario de la transición y la reorganización de la oposición.

El siguiente epígrafe analiza el complejo proceso de transición, los "enclaves autoritarios" dejado por los militares y los dos momentos históricos para encauzar la redemocratización chilena. El primero de ellos es el triunfo del no en el plebiscito, que impidió que Pinochet se perpetuara en el poder. El otro es la elección presidencial que llevó al gobierno a Patricio Aylwin, el primer presidente civil electo después de casi dos décadas de dictadura. Por último, se tejen una serie de comentarios sobre la redemocratización chilena y el desafío de convivir con una democracia tutelada por la sombra castrense.

\section{ENTRE TRANSICIONES Y TENSIONES}

Con el bombardeo al Palacio de la Moneda, los militares chilenos mostraron sus credenciales y el "modus operandi" de lo que sería la presencia castrense en los días posteriores a la ruptura institucional chilena y al fin del gobierno socialista de la Unidad Popular. A partir de ahí se desataría una violenta represión contra los miembros del gobierno y de los partidos de izquierda, además de líderes estudiantiles, sindicales, artistas e intelectuales.

Los actos y los gestos evidenciaron que la derrocada del presidente Salvador Allende y la "vía chilena al socialismo"2 no sería algo provisorio destinado a restaurar el orden y, posteriormente, convocar a elecciones como lo pensaron

\footnotetext{
2 La "vía chilena al socialismo", postulada por Allende y la Unidad Popular, fue un experimento político que proponía la transición pacífica al socialismo a través de los instrumentos legales de la institucionalidad chilena. Nacionalizó los recursos minerales del país y estatizó los medios de producción despertando una fuerte reacción a nivel nacional e internacional. Su desarrollo se dio dentro del contexto de la Guerra Fría, de la Doctrina de Seguridad Nacional (DSN), con Sudamérica infestada de dictaduras militares, tales como Brasil, Paraguay, Argentina, Perú y Bolivia. Su proyecto se nutría de las contribuciones teóricas de la Teoría Marxista de la Dependencia, del debate sobre Reforma y Revolución, y de un diálogo convergente con las corrientes de la Teología de la Liberación.
} 
algunos políticos de la Democracia Cristiana e, incluso, ciertos militares que habían conjurado el día del golpe (Villagrán, 2002).

Sin embargo, la vía chilena se iba diluyendo y se hacía difícil alcanzar el consenso en un ambiente de intolerancias entre los poderes constituidos y los respectivos protagonistas políticos de esa contienda (Bandeira, 2008; Kissinger, 1979; Yofre, 2000). La espiral de polarización política y los enfrentamientos entre grupos, defensores del gobierno y los paramilitares de "Patria y Libertad", amplificaron las contradicciones e impases con la legalidad burguesa y capitalista. Concomitantemente, se quería respetar y sustituir dicha legalidad configurando una incompatibilidad entre la vía legal y la necesidad de ruptura de esa legalidad para la implantación del socialismo (Aggio, 2008).

Desde mediados de 1972 hasta septiembre de 1973, la latencia de una ruptura del orden democrático fue adquiriendo fuerza, impulsada por una oposición política que apeló abiertamente al recurso a la huelga, al sabotaje y a la intervención militar para la derrocada del gobierno socialista. Dichas acciones tuvieron como trasfondo las acciones encubiertas del gobierno de los Estados Unidos que, desde 1964, ya operaba en el país para salvaguardar sus intereses económicos y geoestratégicos de su zona de influencia (Kornbluh, 2003).

Ese desenlace dramático puso fin a la democracia chilena, cuya sociedad se destacaba por sus luchas y movimientos sociales que fueron aglutinando y construyendo una identidad colectiva a partir de demandas por vivienda desde antes del gobierno de Allende (Garcés, 2002). Posteriormente al paro de octubre de 1972, el protagonismo popular creció y su autonomía se vio materializada en los "cordones industriales". Esta iniciativa cuestionaba el poder moderador del Partido Comunista, de la Central Única de los Trabajadores (CUT) y del gobierno, creando un incómodo paralelismo sindical (Gaudichaud, 2004), configurando una "acción directa desde abajo" (Winn, 2004, p. 201), experiencia que en septiembre de 1973 desató el ruido de sables (Sader, 1982).

La junta militar que asumió el poder desató una fuerte represión contra miembros del gobierno depuesto y de los partidos de izquierda caracterizándose, además, por la verticalización del poder en manos del ejército y la personalización del mismo en la figura del general Augusto Pinochet ${ }^{3}$. Al final de la década de 1970, Pinochet ya controlaba el país militarmente en su lucha contra el marxismo y la Dirección de Inteligencia Nacional, la conocida DINA, ya se había

\footnotetext{
${ }^{3}$ Sobre la dictadura chilena y el general Pinochet existe una vasta literatura y perspectivas, entre las cuales se puede consultar: Correa \& Subercaseaux, 1996; Huneeus, 2000; Pinochet, 1990-1994; Rojas, 1998; Vial, 2002, entre otros.
} 
encargado de eliminar, encarcelar o enviar al exilio a los principales líderes de los partidos políticos proclives al gobierno de Salvador Allende (Dorat \& Weibel, 2012).

La DINA, actuando bajo el mando del general Manuel Contreras, se encargó de diseminar dentro del país un clima de terror, miedo y silencio. Sus acciones represivas no se limitaron al territorio chileno, ya que se extendieron más allá de las fronteras nacionales, ejecutando atentados contra políticos y militares en el extranjero ${ }^{4}$. Dichas acciones representaron el preámbulo de lo que posteriormente se conocería como "Operación Cóndor", una red sistemática de cooperación internacional de los organismos de inteligencia de los países sudamericanos destinada a monitorear, perseguir, secuestrar o eliminar a disidentes políticos que se encontraban en el exilio y que representaban una potencial amenaza para el régimen.

En ese ambiente de violencia política y falta de libertades se impuso el binomio formado por la represión política y la doctrina económica neoliberal instaurando, al mismo tiempo, un régimen político y un sistema económico en una situación de "completo vacío de poder" (Gómez, 2001, p. 263). El objetivo era refundar el país, anular el protagonismo estatal y su intermediación entre sociedad y política entregando a la iniciativa privada los pilares más relevantes de la economía y de los servicios públicos.

El neoliberalismo, introducido por los economistas de la Escuela de Chicago y sus "Chicago Boys" posterior a la intervención militar, rasgó el tejido social y político impactando directamente en el ejercicio público de la sociedad y en el acceso a los servicios esenciales como la salud o la educación, entre otros, los cuales fueron transformados en lucrativas actividades de carácter privado. Al

\footnotetext{
${ }^{4}$ El 30 de septiembre de 1974, en Buenos Aires, Argentina, el general del ejército chileno Carlos Prats falleció junto a su esposa en un atentado con bomba ejecutado por la DINA. Prats fue comandante en jefe de las Fuerzas Armadas y ministro del gobierno Allende. Un año después, el 6 de octubre de 1975, el ex ministro de la Democracia Cristiana, Bernardo Leighton, fue baleado junto a su esposa en el centro de Roma, la capital italiana. Ambos sobrevivieron, pero las balas dejaron secuelas en sus cuerpos. Pero el caso que más impactó a la opinión pública nacional y extranjera fue el atentado con bomba sufrido por el ex ministro de Salvador Allende Orlando Letelier y su secretaria, el 21 de septiembre de 1976, en pleno centro de la ciudad estadounidense de Washington. Ese asesinato fue considerado el primer acto terrorista de un gobierno extranjero dentro de los Estados Unidos.

${ }^{5}$ Se denomina "Chicagos Boys" al grupo de economistas chilenos formados en la Pontificia Universidad Católica y en la Universidad de Chile que hicieron sus estudios de posgrado en la Universidad de Chicago, Estados Unidos, en la década de 1960. Estudiaron a fondo la economía chilena y la posibilidad de implantar el ideario neoliberal en ese país, iniciativa que se adecuaba a los intereses de EE. UU. en el continente para contener la expansión del comunismo en la región.
} 
detrimento del espacio público, se incorporó la fragmentación del quehacer democrático y del espíritu gregario, pilares estructurantes y representativos de la sociedad chilena hasta la fecha del golpe de Estado y del consecuente hiato institucional.

El modelo económico alteró profundamente las relaciones laborales y los derechos de huelga y reunión, transfiguró la administración de bienes públicos privando a los ciudadanos del derecho de participar en las decisiones gubernamentales. Junto a eso, se instauró una sistemática privatización de las empresas públicas de relevante protagonismo en el área productiva. Muchas de ellas fueron transferidas a grupos económicos nacionales o, incluso, extranjeros que apoyaron o pactaron con el quiebre institucional. Dichas empresas se caracterizaban por su rol estratégico y su rentabilidad económica, como las del área química, siderúrgica, eléctrica y de telecomunicaciones (Mönckeberg, 2001).

Los medios de comunicación permitidos por los militares fueron piezas claves en el trabajo de legitimar socialmente el ideario neoliberal como la única fórmula posible, no ideológica, para enfrentar los problemas económicos que aquejaban a la población. En sintonía con ese proyecto, la represión y el terror estatal llevaron adelante la obra de militarizar la sociedad e imponer el silencio y el miedo. Ello impactó sensiblemente en la forma cómo la población se relacionó con el Estado, los militares, la política y, principalmente, con su memoria histórica, hecha rehén del trauma colectivo que fue erosionando libertades y conformando una creciente indolencia con relación al ámbito público y sus demandas.

Los centros de detención y tortura se extendieron geográficamente por el país haciendo de los apremios y la eliminación física de sus opositores un sombrío mecanismo de control social para instituir el régimen más allá del golpe. El esfuerzo por extirpar la ideología marxista que representaba el gobierno de Allende se extendió, primero al cuerpo físico y síquico de los disidentes para, posteriormente, extenderse al grueso de la población. Acciones que, en palabras de Moulian, caracterizaban actos de terror:

Terror es la capacidad absoluta y arbitraria de un Estado de inventar, crear y aplicar penas o castigos sin más límites que las finalidades que se ha definido, ... la capacidad de un Estado para conseguir el acuerdo de muchos ciudadanos, que se autoconciben como pacíficos y tolerantes, para usar violencias y daños contra los enemigos políticos, en nombre de un bien mayor (Moulian, 1997, p. 22).

Sin embargo, era imprescindible darle un carácter legal al gobierno militar con un andamiaje institucional que pudiera ofrecerle el reconocimiento 
nacional e internacional. Junto a eso, se hacía necesario neutralizar las presiones sobre la violencia de la policía política en el interior del país y los atentados en el extranjero contra civiles y militares opositores, además de atenuar los efectos de la crisis del petróleo que comprometió el optimismo de las proyecciones del modelo neoliberal en curso. La solución para ese impase fue la elaboración de un nuevo texto constitucional destinado a apuntalar al régimen contra supuestas amenazas de grupos o fuerzas ajenas al nuevo orden. Para ello, se declaraba ilegal todo acto que fomentara la lucha de clases y atentara contra la familia chilena.

Para corporificar el nuevo proyecto de poder, los militares decidieron contar con el apoyo de civiles para poder contribuir con ideas y darle más legitimidad al proyecto constitucional. Una dualidad que, en la perspectiva de Genaro Arriagada, se configuró como el inicio de un régimen cívico-militar ya que dicha circunstancia:

Mostró dos formas de integración de los civiles al gabinete. Una, inorgánica, como individuos aislados, que acudían a aportar sus habilidades y puntos de vista personales, por el periodo que les fuera requerido. Otra, 'en forma de un equipo', capaz de contrapesar ciertas tendencias del mundo militar y ofrecer, al propio régimen, un proyecto determinado (Arriagada, 1998, p. 77).

A medida que crecía la radicalización política durante el gobierno de Allende, esos civiles se aproximaban a los círculos empresariales con los cuales comulgaban en su aversión al nacional desarrollismo, a la democracia participativa, así como al anticomunismo (Chateau Garate, 2012). Sin embargo, a partir de junio de 1972, se suma a ellos un grupo de militares que comienza a reunirse habitualmente en la "Cofradía de Lo Curro" (González, 2012) para elaborar una arquitectura conspirativa que, posteriormente, resultaría en el golpe de Estado y la instauración de una dictadura caracterizada por una dupla racionalidad: económica y coercitiva (Huneeus, 1997).

Una vez controlado militarmente el país y la disidencia, ese aporte civil se hizo patente en el nuevo texto constitucional que se adaptaba a las contingencias nacionales, así, el 11 de septiembre de 1980 la población fue llamada a votar bajo estrictas normas de restricción de la libertad de expresión, de reunión y de información. Sin embargo, la falta de registros electorales y de órganos de fiscalización no impidió que la Constitución se aprobase con un $67 \%$ de votos a favor y un $30,2 \%$ contra. De esa forma, se oficializaba un conjunto de leyes reguladoras que deberían regir transitoriamente a partir del 11 de marzo de $1981 \mathrm{y}$, plenamente, a partir del 11 de marzo de 1990 cuando los militares entregarían el poder a los civiles. 
Se garantizaba así, no sólo la perpetuación del poder castrense sino el control de áreas claves de la dinámica socioeconómica chilena como el sistema financiero, el sector de servicios, los medios de comunicación, la educación principalmente la superior- y el control -y consecuente privatización- de importantes empresas del país. A pesar de todo el esfuerzo por entregar empresas estratégicas del Estado al sector privado, la dictadura pinochetista se esforzó en preservar el carácter estatal de la Corporación Nacional del Cobre (CODELCO) y de la Empresa Nacional de Petróleo (ENAP).

En octubre de 1975, los militares promulgaron el Decreto Ley 1530, que obligaba a la empresa CODELCO a destinar el 10\% de sus ventas anuales a las Fuerzas Armadas para la compra de armamentos. Sin embargo, dichos recursos se mantuvieron en estricto secreto y fuera de cualquier control institucional hasta hacerse público el escándalo conocido como "Milicogate” que involucraba a los altos mandos del Ejército en su desvío y malversación. La cuestionada Ley de Reserva del Cobre fue derogada a través de la Ley 21174 del 26 de septiembre de 2019, estableciendo un nuevo sistema de financiamiento para las Fuerzas Armadas a partir de la ley de presupuesto del sector público, basado en la ponderación anual de recursos disponibles para dicha finalidad.

La arquitectura institucional dilataba el dominio castrense y contemplaba, además de la propia Constitución, la instauración del Consejo de Seguridad Nacional, de los senadores no elegidos y los límites a la autoridad del presidente para remover a los comandantes militares (Barros, 2005). Pinochet posicionaba estratégicamente sus piezas en el tablero político evitando, a corto o medio plazo, la emergencia de cualquier adversario civil o militar que pretendiera contestar o arrebatarle el poder preservando, de esa forma, el carácter personalista, vertical y concentrador de sus decisiones.

Dos años después del plebiscito, Chile ya sentía los efectos de la recesión mundial que marcó la década de los ochenta y que lo afectó de forma directa, por ser un país que dependía predominantemente del mercado externo. Ello generó malestar entre la clase trabajadora, en los estudiantes y en diversos sectores de la sociedad que comenzaron a organizarse y a convocar las primeras protestas a nivel nacional. El año de 1983 marcó un punto de inflexión en la lucha democrática, llevando a la calle a diversos sectores de la sociedad civil que desafiaron el proyecto político dictatorial y, gradualmente, rompieron el miedo y el silencio en masivas manifestaciones. Pinochet no tardó en responder sacando el ejército a la calle, desatando una violenta onda represiva y dejando un número considerable 
de detenidos, heridos y muertos, realidad que no se veía desde los primeros meses del golpe de 1973.

Las protestas del año 1983 se extendieron, favoreciendo la reorganización de las fuerzas opositoras y demandando canales de diálogo con el régimen para alcanzar acuerdos mínimos de cara al plebiscito de 1988 y el retorno gradual a la democracia. Ese año sería un momento crucial, ya que, además de someter a voto popular el régimen del general Pinochet, permitiría calibrar la capacidad, tanto de los militares como de la oposición, para ceder o resistir en sus respectivas posiciones e incorporar nuevos actores a la mesa de negociaciones.

El 5 de octubre de 1988 la sociedad chilena debería elegir entre el sí -la opción que le daba la continuidad a Pinochet-y el no, lo que implicaba establecer un calendario concreto para el fin de la dictadura. El no obtuvo una mayoría absoluta con un 54,7\%, fortaleciendo a la oposición que supo aprovechar los espacios de libertad autorizados por el régimen, tales como el acceso a la prensa, a la campaña en televisión y a las concentraciones que movilizaron grandes contingentes. Este hecho impuso al gobierno militar la necesidad de apaciguar los ánimos y dar los primeros pasos en dirección al proceso de transición democrática.

\section{TRANSICIÓN DEMOCRÁTICA, ACUERDOS, EXPECTATIVAS, DESENCANTOS}

El triunfo de la oposición en octubre de 1988 fue el punto de partida para un complejo, tenso y complicado proceso de negociación que enmarcó la transición chilena y el cambio de régimen, de dictadura a democracia, con la participación masiva de sectores populares. Todo auguraba cambios profundos en el contexto político chileno. Se hicieron 54 modificaciones a la Constitución de 1980, las cuales fueron respaldadas por un nuevo plebiscito en Julio de 1989, que obtuvo un $85,7 \%$ de aprobación. Sin embargo, en esos últimos meses de 1989, Pinochet preservó los nueve senadores designados, la mayoría de ellos militares en retiro y que tendrían una considerable influencia en el equilibrio de fuerzas del parlamento, además del sistema electoral binominal (Huneeus, 2006).

Esos dos obstáculos en el tortuoso camino hacia la redemocratización los senadores designados y sistema binominal- representaron la infantería política de Pinochet destinada a enfrentar la batalla en su propio terreno: la constitución de 1980. Después de casi dos décadas de vetos al ejercicio del poder ciudadano, la sociedad chilena tuvo que convivir con un modelo de sufragios binominal. Dicho recurso le otorgaba a Pinochet una representatividad electoral del 50\%, 
haciendo que la oposición fuera obligada a conquistar un margen superior al $65 \%$ para alcanzar la mayoría en los pleitos en disputa.

La Constitución de 1980, criticada por ser antidemocrática y escrita bajo un régimen de fuerza, se transformó en el texto legal a partir del cual sería negociada la transición, hecho que de antemano legitimaba dicha Carta Magna y configuraba una flagrante discrepancia entre los actores en pugna. La oposición tenía una dura tarea por delante que implicaba en remover los denominados "enclaves autoritarios" (Garretón, 1989). De esta manera se definían los artificios que el régimen militar utilizaría para garantizar una democracia tutelada, con una ley electoral que proscribía agrupaciones de izquierda que postulasen, entre otras, la lucha de clases. Ello suponía marginar directamente al Partido Comunista ${ }^{6}$, además de salvaguardar a las Fuerzas Armadas contra posibles juicios por violaciones a los derechos humanos. De acuerdo con Garretón, esos enclaves:

[...] pueden ser institucionales (Constitución, leyes, etc.), "actorales" (Fuerzas Armadas con poder de veto, derecha no democrática, etc.), socioculturales (valores autoritarios, conformismo, etc.) o ético-simbólicos (problemas de derechos humanos no resueltos), y las estrategias frente a ellos pueden ser de diversos tipos (legales, presión, etcétera) (Garretón, 1991, p. 104).

El triunfo del no marcó el itinerario de la transición destinada a consolidar la democracia, pero la Concertación tenía de por medio difíciles acuerdos políticos y complejas negociaciones con los militares. Estas incluyeron la permanencia del dictador como comandante en jefe del Ejército y su incómodo rol en el parlamento chileno como senador vitalicio. Ese periodo transitorio entre el triunfo del no y las primeras elecciones después del golpe de Estado se enmarcó, primero, en una agenda definida por el régimen militar y para la cual la oposición no tuvo autonomía decisoria ni un margen de acción favorable y; segundo, los calculados movimientos en el tablero de la transición llevaron a la oposición a aceptar la Constitución de 1980 como el marco legal de referencia para el cambio de régi-

\footnotetext{
${ }^{6}$ El PC chileno no consiguió erguirse como fuerza política relevante durante la transición. Ello se explica debido a sus disputas internas, las cuales se agravaron después del fracasado atentado a Pinochet, en 1986, realizado por su brazo armado, el FPMR, y se acrecentaron por la crisis del socialismo real, en 1989, y la inviabilidad de su Política de Rebelión Popular de Masas (PRPM). Esos factores, y su disposición a no pactar con el régimen de Pinochet, contribuyeron para aislarlo del Acuerdo por el NO y de la Concertación, dejándolo en una posición minoritaria durante el proceso de redemocratización, restándole como opción participar en la alianza del Partido Amplio de Izquierda Socialista (PAIS), con escasos resultados electorales. Además, pesaba sobre la agrupación la ley electoral de la Constitución de 1980 que, en su artículo $8^{\circ}$, prohibía a los partidos que "atenten contra la familia, propugnen la violencia o una concepción de la sociedad, del Estado o del orden jurídico, da carácter totalitario o fundada en la lucha de clases" (Constitución política de la República de Chile).
} 
men y, de ese modo, enfrentar la batalla contra Pinochet en la arena de su propia institucionalidad.

El punto de convergencia de esos acuerdos fue alcanzado en junio de 1989 cuando los partidos políticos y el gobierno militar llegaron a un consenso con relación a las reformas constitucionales necesarias para el traspaso del poder a los civiles. Sin embargo, los militares ya habían iniciado los preparativos con un año de anterioridad y, entre el 5 de octubre de 1988 y el 11 de marzo de 1990, fecha que marcó la entrega del gobierno al presidente electo, la Junta de Gobierno y Pinochet promulgaron 226 leyes que aseguraban el proyecto político autoritario defendido por las Fuerzas Armadas y sus aliados civiles (Huneeus, 1997).

Consensuados los puntos neurálgicos de las reformas, la población chilena fue convocada a las urnas para elegir al primer gobierno democrático después de diecisiete años de dictadura. Después de la victoria opositora en el plebiscito y las reformas constitucionales, la elección presidencial del 14 de diciembre de 1989 fue el momento más relevante que se sumaba a una doble euforia: la de un año antes que había impedido la permanencia de Pinochet en la presidencia chilena y las elecciones para poner fin a la dictadura, todo un giro en la perspectiva temporal da la política chilena que en los años sesenta y setenta reclamaba por una revolución pero, en los ochenta, demandaba democracia (Lechner, 1998).

La victoria en las elecciones la obtuvo el candidato de la Concertación, Patricio Aylwin, con 55,2\% de los votos; el segundo colocado, con un 29,4\%, fue Hernán Büchi, candidato por la alianza Democracia y Progreso, ex ministro de Hacienda del régimen militar e ideólogo de las reformas neoliberales implantadas en Chile; y el tercero, con un $15 \%$ de los sufragios fue el empresario Francisco Errázuriz, independiente. El triunfo electoral de Aylwin fue proclamado tanto por la derecha política, atenta al nuevo ciclo de poder sin Pinochet, como por parte de la izquierda agrupada en la Concertación, incluyendo a ex allendistas que deciden pactar junto a la Democracia Cristiana ${ }^{7}$ y que reconocían como presidente

\footnotetext{
${ }^{7}$ Para la fase de transición, la oposición a Pinochet formó la Concertación por el NO, compuesta por 17 agrupaciones políticas. Posteriormente formaron la Concertación de Partidos por la Democracia compuesta básicamente por socialistas agrupados en el Partido por la Democracia (PPD) y democratacristianos que decidieron enfrentar al régimen a través de la propia institucionalidad política eligiendo a un candidato único, Patricio Aylwin. Sin embargo los socialistas, se presentaron divididos, una división que venía desde el exilio con el grupo de Altamirano, que se incorpora al PPD, defendiendo una transición pacífica y un acuerdo con la Democracia Cristiana; ya el PS de Almeyda, más ortodoxo y defensor de una vía insurgente contra el régimen de Pinochet, decide formar una alianza con el PC a través del Partido Amplio de Izquierda Socialista (PAIS). El fracaso electoral del PAIS, en 1989, favoreció su adhesión posterior a la Concertación y a una unidad temporaria de las dos corrientes socialistas.
} 
a un político, después de que este hubiese alentado el golpe y defendido la legitimidad del proceder de Augusto Pinochet (Cárdenas, 2009, p. 28).

La ceremonia de transferencia del mando presidencial tuvo un riesgo adicional e imprevisible. El nuevo presidente tuvo que gobernar con la presencia de Pinochet como Comandante en Jefe de las Fuerzas Armadas durante ocho años, de 1990 hasta 1998, lo que políticamente se traducía en una incómoda interlocución entre el poder civil y el militar. Dicha fricción se amplificó con el nombramiento de Pinochet como senador vitalicio en 1998.

Aylwin gobernó de 1990 a 1994 pero, además de convivir durante esos cuatro años con la sombra del general y tener que administrar el modelo económico neoliberal heredado de régimen militar, el primer mandatario tuvo que hacer frente a la dura tarea de concluir la transición y restablecer la democracia bajo la tutela castrense.

Además, tuvo que lidiar las tensiones relacionadas con las violaciones a los derechos humanos, ya que el espectro de la impunidad contaminaba la incipiente democracia como condición sine qua non para la estabilidad económica y política del país (Nash, 2016). Durante el mandato de Aylwin, el informe de la Comisión de Verdad y Reconciliación Nacional $(1990)^{8}$ registró más de 3.000 casos de muertes y desapariciones como resultado de torturas, ejecuciones extrajudiciales o desapariciones forzadas, revelando parcialmente la herencia sombría del pasado.

Sin embargo, dejó en evidencia el incumplimiento estatal con la justicia y los derechos humanos, así como la omisión oficial y el negacionismo cómplice de los mandos militares que se empeñaron en sepultar las informaciones como un "enclave" no declarado y amparado por la ley del silencio (Fernández, 2010). Atento a la investigación sobre las violaciones a los derechos humanos, consecuencias que recaerían sobre sus estrechos colaboradores, Pinochet decidió disolver, en febrero de 1990, la Central Nacional de Informaciones (CNI), sucesora de la Dirección Nacional de Informaciones (DINA), órgano de represión política, responsable por inúmeras prisiones, torturas y muertes de opositores.

Si los impases y restricciones impuestos al periodo de transición dejaron un ambiente favorable para un acuerdo nacional, por otro fue relativizado por un mar de dudas, recelos y desconfianzas (Boeninger, 1997, p. 369). Un exhaustivo proceso que implicó mantener los pilares centrales del régimen pasado evitando rupturas e iniciativas contrarias al proyecto autoritario. Los protagonistas se em-

\footnotetext{
${ }^{8} \mathrm{El}$ informe puede consultarse en: http://www.gob.cl/informe-rettig/
} 
peñaron en evocar los principios democráticos y la relevancia de ese momento histórico resultó en un calculado "transformismo" (Moulian, 1997). Ello implicó promover cambios bajo un nuevo ropaje, resultando en la permanencia de estructuras destinadas a inviabilizar la dinámica política del ejecutivo en democracia, así como generar obstáculos para el cotidiano parlamentar y la promulgación de leyes orientadas a una sociedad libre de tutelas.

Los esfuerzos por preservar la arquitectura institucional trazada por la Constitución Política del dictador Augusto Pinochet hizo emerger los intereses de la burguesía chilena, un grupo que se mantuvo fiel al régimen militar desde septiembre de 1973 y que vio con preocupación el movimiento popular que llevó al plebiscito y a las elecciones presidenciales. Después de haber alentado la ruptura institucional y haberse favorecido económica y políticamente durante los años de dictadura, ese grupo intenta distanciarse de los militares participando en los acuerdos de la transición, ocupando espacios estratégicos que le permitan la influencia política y la gestión directa del Estado (Marini, 1985).

Entramada en el tejido empresarial y gremial, la burguesía chilena actuó como interlocutora en el ámbito económico y contribuyó activamente en la conducción del proceso de privatización de empresas en clave neoliberal durante los años posteriores al golpe de Estado. Entretanto, la crisis económica de la década de 1980 y las consecuentes protestas llevaron al régimen a optar por una tímida apertura, lo que favoreció a la refundación de la derecha local en dos agrupaciones partidarias: la Unión Democrática Independiente (UDI) y la Renovación Nacional (RN) (Moulian \& Torres, 1988).

A través de esas plataformas partidarias les fue posible defender pilares básicos de su ideario político, como la libertad económica y la propiedad privada, pero, además de eso, un modelo de democracia donde fuera posible preservar la arena parlamentaria. Era ese escenario político donde podrían obtener las mayorías necesarias para impedir cambios substanciales, sea de modo directo o mediado por los grupos parlamentarios a su servicio (Marini, 1985). Desde la trinchera legislativa serán agitadas las iniciativas destinas a combatir y limitar el campo de acción del Estado como regulador, delegando dicha atribución al parlamento a través de leyes específicas o directamente a la iniciativa privada.

El rol desempeñado por la derecha chilena antes, durante y, principalmente, en la fase de transición democrática, converge con las afirmaciones de Manuel Antonio Garretón, al afirmar que, tanto en Chile como en el resto del continente, el principal enemigo de la democracia burguesa es la burguesía (Garretón, 1987, p. 72). En momentos de impase o tensión política, la burguesía ha 
combatido sin cuartel la democracia vigente e, inconsecuentemente, su propia institucionalidad burguesa. En nombre de la sagrada libertad económica han sido tolerantes o cómplices a la hora de implosionar el edificio democrático o, si se piensa específicamente en el caso chileno, se han mostrado implacables a la hora de ofrecer las libertades políticas como sacrificio en el "altar de Milton Friedman".

Sin embargo, el modelo neoliberal defendido por la burguesía chilena difería sensiblemente del modelo económico liberal clásico, anclado en una formulación filosófica y sociopolítica que gravitó en las primeras décadas del siglo XX. El neoliberalismo que los "Chicago Boys" implantaron en Chile tuvo como características esenciales su reduccionismo economicista, un cierto desprecio por el ámbito de lo público, además de una marcada ambigüedad en torno a la democracia como forma política de gobierno (Walker, 2006, p. 7).

Esa misma ambigüedad acompañó al gobierno de Patricio Aylwin, que pasó sus cuatro años como presidente de la república desactivando las minas dejadas por los "enclaves" donde lo más importante no dependía de quien gobernaba el país, sino más bien de cuánto poder tenga el que acceda a la conducción del Estado (Guzmán, 1979, p. 18). La transición democrática chilena en la cual la sociedad depositó grandes esperanzas, fue delineada en 1979 por uno de los ideólogos del proyecto constitucional de 1980, Jaime Guzmán, que profetizó el alcance de la Carta Magna autoritaria y el rol que tendría en una futura transferencia de poder a los civiles.

Como visionario de la política del régimen, el abogado Guzmán, miembro de la Comisión Elaboradora del Anteproyecto Constitucional, se anticipó a los hechos afirmando que:

Es decir, que si llegan a gobernar los adversarios, se vean constreñidos a seguir una acción no tan distinta a la que uno mismo anhelaría, porque - valga la metáfora - el margen de alternativas que la cancha imponga de hecho a quienes juegan en ella sea lo suficientemente reducido para ser extremadamente difícil lo contrario (Guzmán, 1979, p. 19).

Así se proyectaban las reales limitaciones que la matemática parlamentaria y el reducido margen de acción que el tutelaje del marco legal de 1980 imponía del ejecutivo en su quehacer democrático. Todo ello en pos de parar los pies a un futuro gobierno de transición extendido a los gobiernos civiles que sucederían a Aylwin. Esa realidad fue distanciando a los chilenos del anhelado horizonte democrático, negado durante años de silenciosos temores, derechos cercenados y cuerpos atormentados y que, ahora, luchaban contra la amnesia y las políticas de desmemoria (Richard, 2000). Una lucha que evocaba palabras como 
libertad, democracia y partidos, sin olvidar aquellas que demandaban justicia, derechos, condena para los agentes del terror y cambios profundos no ámbito social, político y económico en dirección a una sociedad más equitativa y digna.

\section{CONSIDERACIONES FINALES}

Con la elección de Patricio Aylwin y su asunción en marzo de 1990 como el primer presidente chileno posterior a la dictadura, el proceso de transición a la democracia entró en un laberinto de ambigüedades en que, entre el espíritu festivo de la población y las palabras oficiales impregnadas de cautela y moderación, se impuso una gramática política que incluyó concesiones, acuerdos velados y disimulados privilegios. A los pocos meses de asumir un presidente civil los destinos del país, los fenómenos apuntados comenzaron a colidir con las expectativas que la población había depositado en el proyecto democrático de la concertación. Las casi dos décadas de autoritarismo entorpecieron la dinámica del quehacer político de la ciudadanía y de sus respectivos actores, lo que dejaba en evidencia la precaria representatividad en las esferas de poder y la mínima interlocución a la hora de incidir sobre el incipiente proceso de redemocratización que gravitaba sobre la sociedad.

Los 17 años de militarización de la sociedad chilena dejaron secuelas que legitimaron comportamientos y posturas propias de la verticalización y personalización del poder. Estas se proyectaron en el periodo de transición y en la nueva configuración de los poderes constituidos en democracia. Sin embargo, el torrente reivindicativo popular rompió la olla de presión del miedo y de las violentas arbitrariedades de la represión política, llevando a los ciudadanos chilenos a ocupar los espacios públicos después de años de indiferencia y postergación de sus derechos y, finalmente, a protagonizar los cambios políticos y sociales a través del ejercicio ciudadano del voto.

El clima político era auspicioso, recomendándoles a las nuevas autoridades una interlocución en favor de las mayorías postergadas y una agenda permeable a sus demandas, reclamos que contemplaban aspectos imperiosos, como el laboral, el educacional o el económico, entre otros. Entretanto, entre las herencias del régimen militar se encontraba el modelo económico de corte neoliberal que, desde 1985 mantuvo cierta recuperación y estabilidad hasta finales de la década siguiente. Dicha realidad llevó al nuevo gobierno a definir prioridades en el ámbito económico imponiendo una disciplinada obediencia con los creedores internacionales y el equilibrio interno del país. 
Los pleitos más apremiantes de la población, que permitirían cimentar una sociedad democrática, se diluían en el medio de los discursos oficiales con el argumento de que los buenos índices macroeconómicos serían suficientes para atender esas reivindicaciones a medio plazo. Las esperanzas depositadas en la naciente redemocratización no tardaron en verse frustradas, diseminando la desilusión en una parte importante de la población, cansada de ver sus derechos postergados y de convivir con una cultura política prepotente, intolerante y poco receptiva al quehacer democrático y a las inequidades sociales.

Las inconvenientes permanencias y continuidades del régimen militar eran incompatibles con una transición democrática y con el vigor de las movilizaciones sociales que apostaron por un nuevo pacto social y por un gobierno empeñado en cautelar los efectos de la fractura social. Realidad que gravitó sobre el gobierno de Patricio Aylwin y que se mantuvo en gobiernos posteriores, como el de Eduardo Frei Ruiz-Tagle, Ricardo Lagos y Michelle Bachelet, sin alterar las piezas del tablero responsable por la transición.

Además de subordinar la cuestión social al modelo económico, el gobierno Aylwin enfrentó el sensible impase sobre los derechos humanos y las responsabilidades de los militares en los macabros hechos de los desaparecidos y las víctimas de la represión. A pesar de los avances en ese sentido, no fue posible disipar la sombra castrense y los intentos por eclipsar la transición, externando amenazas destinadas a interrumpir el tránsito de esa compleja y difícil redemocratización. Los pasos y contrapasos de ese conturbado proceso hicieron de la transición un espejismo. Así, el autoritarismo del pasado proveniente de los cuarteles daba paso, ahora, a la rigidez económica del modelo neoliberal y su imperativo macroeconómico. En el ámbito social, la fuerza de las movilizaciones sociales y sus demandas fue siendo gradualmente desactivada por una agenda gubernamental orientada a eliminar el riesgo que podrían generar los extremos, la polarización política y el acumulo de demandas pasible de conflictos.

A pesar de los reflejos tardíos y, aparentemente indolentes de la sociedad civil, los chilenos luchan para preservar viva la memoria. Una memoria marcada por las libertades del pasado democrático y la lucha por sus derechos, que choca radicalmente con el contexto autoritario, marcado por la represión violenta, por el exilio y por la banalidad del consumo como valor humano. Una memoria que active mecanismos de representación política capaces de ofrecer respuestas a las demandas de una sociedad moderna y cada vez más compleja, 
que supere las frustraciones y las expectativas negativas y permita erguir una arquitectura constitucional que no obnubile al Estado, al ciudadano y al espacio público como horizonte democrático.

\section{BIBLIOGRAFÍA}

Aggio, A. (2008, enero). Brasileiros de esquerda no Chile de Allende. Acessa.com. https://www.acessa.com/gramsci/?page=visualizar\&id=845

Arriagada, G. (1998). Por la razón o la fuerza: Chile bajo Pinochet. Sudamericana.

Bandeira, L. A. M. (2008). Fórmula para o caos: Ascensão e queda de Salvador Allende (19701973). Civilização Brasileira.

Barros, R. (2005). La junta militar: Pinochet y la constitución de 1980. Sudamericana.

Boeninger, E. (1997). Democracia en Chile: Lecciones para la g obernabilidad. Andrés Bello.

Cárdenas, J. P. (2009). Un Peligro para la Sociedad. Debate.

Comblim, J. (1978). A ideologia da Segurança Nacional: O poder militar na América Latina. Civilização Brasileira.

Correa, R., \& Subercaseaux, E. (1996). Ego Sum Pinochet. Planeta.

Chateau Garate, M. (2012). La revolución Capitalista en Chile (1973-2003). Ediciones Universidad Alberto Hurtado.

Dorat, C., \& Weibel, M. (2012). Asociación Ilícita: Los archivos secretos de la dictadura. Ceibo.

Fernández, K. (2010). La prescripción gradual, aplicada a los delitos de lesa humanidad [Tesis de maestría, Universidad de Chile]. Repositorio Académico de la Universidad de Chile. http://repositorio.uchile.cl/handle/2250/106747

Fontaine, A. (1988). Los Economistas y el Presidente Pinochet. Zig-Zag.

Garcés, M. (2002). Tomando su sitio: El movimiento de pobladores de Santiago, 19571970. LOM Ediciones.

Garretón, M. A. (1987). La democratización en América Latina. Revista Análisis Politico, (1), 5874.

Garretón, M. A. (1989). La Posibilidad Democrática en Chile. FLACSO.

Garretón, M. A. (1991). La redemocratización política en Chile: Transición, inauguración y evolución. Estudios Públicos, (42), 102-133.

Gaudichaud, F. (2004). Poder Popular y Cordones Industriales: Testimonios sobre el movimiento popular urbano, 1970-1973. LOM Ediciones. 
Gómez, S. (2001). Democratización y globalización: Nuevos dilemas para la agricultura chilena y sus Organizaciones. In N. Giaracca (ed.), Una nueva ruralidad en América Latina (pp. 243-266). CLACSO.

González, M. (2012). La Conjura: Los mil y un días del golpe. Catalonia.

Guzmán P. (1979). El camino político. Revista Realidad, 1(7), 13-23.

Huneeus, C. (1997). La autodisolución de la 'democracia protegida' en Chile. Revista Ciencia Política, (19), 61-86.

Huneeus, C. (2000). El régimen de Pinochet. Sudamericana.

Huneeus, C. (2006). La reforma al sistema binominal en Chile: Propuestas para el debate. Fundación Konrad Adenauer.

Kissinger, H. (1979) Mis Memorias. Atlántida.

Kornbluh, P. (2003). Los EEUU y el derrocamiento de Allende: Una historia desclasificada. Ediciones $\mathrm{B}$.

Lechner, N. (1988). Los patios interiores de la democracia. Fondo de Cultura Económica.

Marini, R. M. (1985). La lucha por la democracia en América Latina. Cuadernos políticos, (44), 3-11.

Mönckeberg, M. O. (2001). El saqueo de los grupos económicos al Estado chileno. Ediciones B.

Moulian, T. (1997) Chile actual: Anatomía de un mito. LOM-Arcis.

Moulian, T., \& Torres, I. (1988). La reorganización de los partidos de la derecha entre 1983 y 1988. FLACSO.

Nash, C. (2016) La transición chilena y justicia transicional: Análisis crítico. Revista Derecho \& Sociedad, (47), 129-144.

Pinochet, A. (1990/1994). Camino recorrido. Instituto Geográfico Militar.

Ramos, R. F. (2020). Sobre transiciones pasadas: La experiencia chilena hacia la democracia (1983-1990). In J. Olivar \& M. Martínez Meucci (eds.), Transiciones políticas en América Latina: Desafios y experiencias (pp. 158-177). Universidad Metropolitana.

Richard, N. (ed.). (2000). Politicas y estéticas de la memoria. Cuarto Propio.

Rojas, G. (1998). Chile escoge la libertad: La presidencia de Augusto Pinochet Ugarte. Zig-Zag.

Sader, E. (1982). Um rumor de botas: A militarização do Estado na América Latina. Polis.

Vial, G. (2002). Pinochet: La biografia. El Mercurio.

Villagrán, F. (2002). Disparen a la bandada. Planeta.

Walker I. (2006). Democracia en américa latina. Cadal Documentos, (54), 2-10. 
Winn, P. (2004). Tejedores de la revolución: Los trabajadores de Yarur y la vía chilena al socialismo. LOM Ediciones.

Yofre, J. B. (2000). Misión Argentina en Chile (1970-1973): Los registros secretos de una dificil gestión diplomática. Sudamericana. 